the gyri and between them. The largest of the hemorrhages may be seen with the naked eye as punctiform. They exist also in the brain substance, usually the white, and are most numerous in the motor region, and in the frontal and temporal lobes, but may be oceasionally found in the other parts of the hemisphere and in the central ganglia. They have all the character of fresh hemorrhages and must have occurred shortly before death. The blood vessels in the pia and in the brain substance are normal. Their walls are not thickened and no infiltration exists around them, but in the parts of the brain

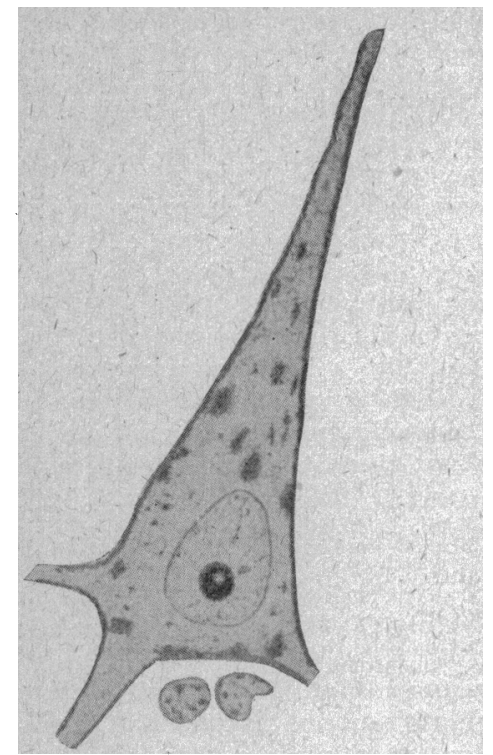

Fig. 5.-Pyramidal cell from the deeper part of cortex. (Leitz system 1/12, ocul. lii.) (Rosin.)

where the hemorrhages are numerous a slight edema is found around some of the veins. There is no measurable change in the thickness of the cortex, and estimations of the number of the ganglion cells have given the same figures as in normal brains. The giant ganglion cells (Betz) are normal, but in the large pyramidal cells and in those of medium size a slight chromotolysis was frequently met with (Fig. 5). In the layers of the medium sized and the small pyramidal eells,

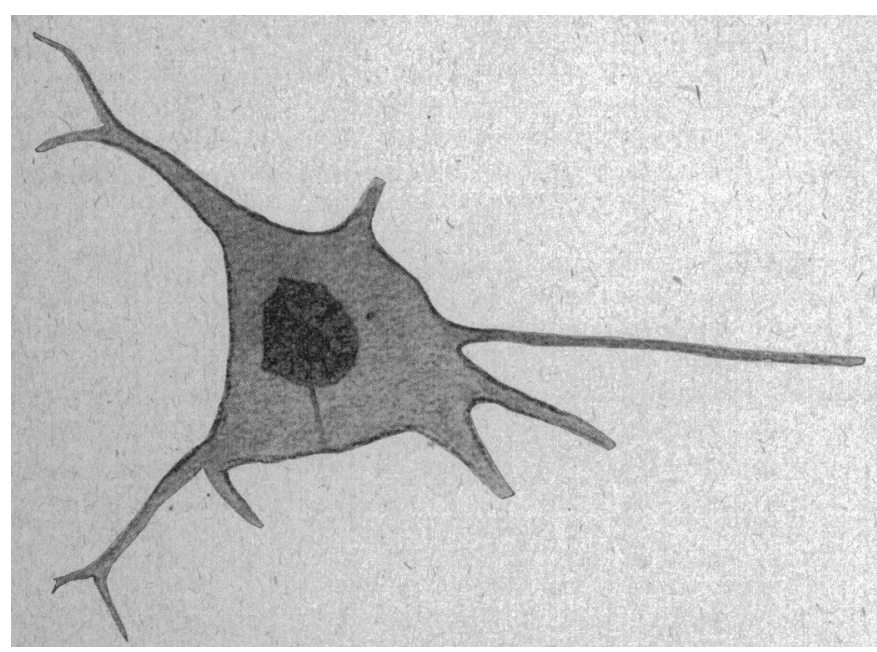

Fig. 6.-Degenerated pyramidal cell from the middle layer of cortex. (Leitz system 1/12, ocul. lil.) (Rosin.)

especially in those parts of the brain that showed numerous hemorrhages, many cells were found showing the degeneration described by Hoche (Fig. 6). The same kind of degeneration was also found in nucleus dentatus.

Notwithstanding repeated trials it has been impossible to stain the' neuroglia with any of the elective methods. There seems, however, to exist a slight increase in the neuroglia nuclei in the motor region and parts of the frontal lobe, but the in- crease is so very slight that $I$ do not venture to decide positively if the glia is increased or not.

The number, size and arrangement of the meduliated fibers correspond perfectly to the normal. In Figs. 7, 8, 9 are reproduced sections from different parts of the brain, and in Fig. 10 a section from a sane man of the same age as the patient.

Section 10 is about 5 microns thicker than the other sections and serves mostly as a control of the reproduction. The thickness of the other sections varies between 15 and $20 \mathrm{mi}$ crons. They show the different strata and the radiating fibers without any perceptible deviation from what normally is found in the corresponding gyri. The ependyma is normal in the lateral ventricles, the aqueductus sylvii and the fourth ventricle. Especially important is that the brain tissue beneath the above mentioned depressions in the frontal lobe was found perfectly normal in all its layers.

The brain can be said to have in general broad gyri, but it does not present altogether well formed and regular gyri and sulci. Although there is nothing in the formation of the gyri and sulci that can be classed as positively pathologic, certain features are worth mentioning. Thus the right frontal lobe does not extend as far back as the left, and several of the gyri give the impression of a conformaution lacking in proportion and symmetry as, for instance, Brocas gyrus, certain parts of the gyri centrales, parietalis and temporalis. Furthermore, an unusual number of deep anastomoses between the great sulci and, finally, the abnormal development of fissura parieto-occipitalis. It may be that the irregularities mentioned have not any significance, but, on the other hand, they may be signs of a faulty development. As heredity is generally considered one of the most important factors in the etiology of circular insanity, it has seemed to me important to look for formations that could possibly indicate a faulty development and to make the material available to comparison with brains from other cases of the same disease, I deemed it necessary to give full description of the gyri and sulci with accompanying drawings. The microscopic examination has, as seen, not given any positive results, except the finding of hemorrhages, the slight cnromatolysis and the Hoches degeneration, and all these changes have their natural explanation in the typhoid fever of which the patient died. But, on the other hand, the microscopic examination has strengthened the clinical diagnosis, making it possible to exclude a dementia paralytica.

One distinct pathologic change has been found in this case and that it is the exostoses with adherent dura. Now the opinion has been expressed that exostoses could perhaps have some influence on the development of a circular insanity by the changes they cause in the cortex. In Dr. Dewey's case, however, there was not found the slightest alteration of the cortex in that part of the brain which was exposed to a supposed pressure of the exostoses, and I can not, under such circumstances, see any reason to suppose that the exostoses have had any influence on the insanity in this case.

\section{SOME GRAPHIC OBSERVATIONS OF ANKLE CLONUS.}

AUGUSTUS A. ESHNER, M.D.

Professor of Clinical Medicine in the Philadelphia Polyclinic; Physiclan to the Philadelphia Hospital; Assistant Physician to the Philadelphla Orthopedic Hospital and Infirmary for Nervous Diseases : Physician to the Hospital for Diseases of the Lungs at Chestnut Hill. PHILADELPHIA.

[From the Philadelphia Orthopedic Hospital and Inflrmary for Nervous Diseases.]

The phenomenon known as ankle clonus consists in alternate extension and flexion of the foot on the leg, repeated a varying number of times, following passive flexion of the foot effected rather rapidly and forcibly and maintained somewhat firmly. It is best induced with the leg flexed slightly on the thigh and supported in the palm of one hand, although it can. at times be 
elicited-as with the patient lying supine in bed-when the leg is fully extended on the thigh. Its presence is, in general, an expression of excessive irritability on the part of the motor path in the lumbosacral segment of the spinal cord, and while it is occasionally observed in cases of neurasthenia and hysteria, it is, as a rule, a sign of organic discase. It can at times be induced in healthy persons by supporting the weight of the body on the ball of the partially extended foot, with the leg flexed moderately on the thigh. Under such circumstances the movement can, and in fact often must, be begun voluntarily, and its continuance requires a certain amount of voluntary contribution. In the presence of organic disease of the nervous system, however, the movement, once begun, continues until it exhausts itself, quite independently of the will of the patient, who can neither induce nor prevent it by this means.

The phenomenon, it is thought, is a reflex brought about through the intermediation of an impulse transmitted to the spinal cord as a result of the tension suddenly applied to the muscles of the calf through the Achilles tendon. The flexion of the foot is effected by the anterior tibial muscles, the extension by the muscles of the calf. The latter is commonly attributed especially to the action of the gastrocnemius, but this can be so only when the leg is extended on the thigh, for it is under such conditions alone that the gastrocnemius is, by reason of its origin from the femur, capable of causing extension of the foot. Ordinarily, however, in the study of ankle clonus, with the leg slightly flexed, extension of the foot is effected principally by the soleus. Both anatomically and physiolog: cally the soleus and the two heads of the gastrocnemius may be looked on as representing the three heads of a tricipital muscle, which do not always act together. The same arrangement is observed in the case of other muscles provided with two or more heads.

According to Gowers, ${ }^{1}$ ankle clonus is characterized by regularity of movement, slight variation in different individuals and in the same individual at different times. $\mathrm{He}$ found the average number of contractions to be near!y 6 in the second. At first he made the limits between 5 and 7 , but more recently he has placed the upper limit at $10 .^{2}$ In obtaining tracings of the movement he has observed the rise of the lever in the kymographic record to be more sudden than its decline, while the actual amount of contraction and the extent of movement vary in different individuals.

On the suggestion of Dr. S. Weir Mitchell, I undertook a series of graphic observations of ankle clonus, in order to determine if, like the knee-jerk, it could be reinforced by motor influences, with the result that such reinforcement was at times appreciable to the hand of the observer in contact with the foot, particularly after the clonus had been going on for some time, and as indicated in some of the tracings in the form of increased frequency of movement. The clonus was in some instances induced by means of the hand applied to the ball of the foot and in other instances by means of traction applied from behind the patient through an elastic band.

Most of the tracings were made with the aid of two tambours, one of which was either connected with the foot by means of a stiff wire or applied directly to the foot, while to the other was fastened a style that re-

1. Medico-Chirurgical Transactions, 1879 , second series, vol. xliv, 269.

2. A Manual of Diseases of the Nervous System, vol. 1, p. 12,
3d ed. corded the movement on the surface of sooted paper mounted on a revolving kymograph. In some instances a rubber bulb was employed instead of the tambour applied to the foot.

To study the normal ankle clonus I made a tracing of the movement of my own feet, obtained by resting rather firmly on the ball of the foot with the leg flexed to a considerable degree on the thigh. I found this not entirely easy of accomplishment, and only with a certain amount of volit:onal contribution. The tracing (Fig. 1) shows a frequency of between $\% .3$ and $\% .6$ in the scond for the right foot, and between 7 and $\tau .4$ for the left foot, taken separately, with irregularity in amplitude and occasional dicrotism. These figures correspond approximately with those obtained by Alexander James, ${ }^{3}$
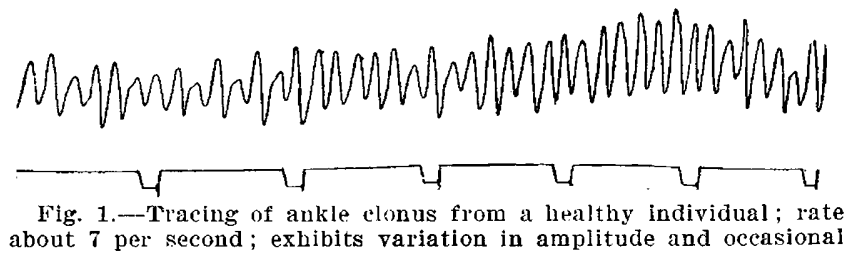
about 7 per second; exhibits variation in amplitude and occasional dicrotism: lead from right to left.

who, in observations on five healthy persons, found the frequency of the movement to range between 6 and 8 in the second. From his further studies of this subject, Jamrs ${ }^{*}$ was led to believe that the rapidity of ankle clonus is in inverse ratio to the height of the individual; that the clonus is more rapid in individuals of nervous temperament as compared with those who appear phlegmatic; that it is more rapid in men who indulge in athletic sports than in those who are !ess active physically; and that it tends to brcome less rapid as age advances.

In a case of hemiplegia I found the frequener of movement to range from 6.6 to 7.2 in the seco d, averaging 6.9 in fifty-seven seconds, with a progressirely lesscning tendency (Fig. 2). The tracing exhibits greit regularity ard a persistent notch between the beginning and the middle of the downstroke of each wave. In a

\section{MWMWMWMWMWMWMMA}

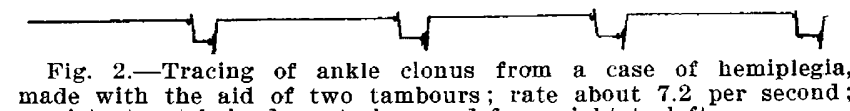
made with the aid of two tambours; rate about 7.2 per second; persistent notch in downstroke; read from right to left.

second observation (Fig. 3) the number of movements varied between 6 and 6.4 in the second. The tracing exhibits great constancy in frequency, in rhythm and in amplitude. It is characterized by a persistent dicrotic notch at the bottom of each wave. There was no apparent effect in any way from attempts at reinforcement, as by clenching the fists, closing the eyes or opening the eyes. The range of movement was far more markcd than in the tracing from myself, and the curve was far more regular, but in this, as in all other tracings from patients suffering with organic disease of the nervous system, the clonus was entirely involuntary.

In a case of myelitis (Fig. 4, Tracings 38, 39, 40), the frequency of movement was extremely variable, becoming, with the amplitude, progressively less, until the movement ceased spontaneously. This would appear to have been due to exhaustion. The average range was

3. Edinburgh Med. Jour., xxvi, i, 1880, p. 135.

4. Ibid., xxviii, ii, 1883 , p. 1075 . 
from 6.4 to $8 \mathrm{in}$ the second. A dicrotic notch appeared at times at the beginning of the upstroke, at other times a little later, and at still other times in the downstroke. It was noted that when the amplitude was greatest the notch occurred in the upstroke, and as the amplitude became less the notch appeared in the downstroke. The curves in this tracing, as in others, exhibit a tendency to group themselves in pairs. Here also no influence appeared to be exerted by clenching and relaxing the hands. (Tracings 39, 40.) fluence of reinforcement was distinctly appreciable to the examining hand, and it was also shown in the tracings in an increase in the frequency of movement. Thus, with the patient passive, the number of movements in the second was quite uniformly 5.8, while, when the hands were clenched, the frequency became increased to 6.8 and 6.9. These tracings exhibit further a grouping of the waves in pairs, and a distinct dicrotic notch or secondary wave in the descending portion of the curve. In this case tremor of the thighs was induced, evidently

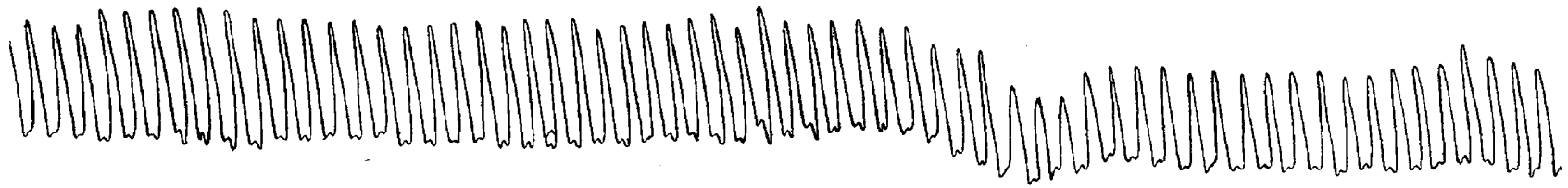

Fig. 3.-Tracing of ankle cionus from a case of hemiplegia; no apparent reinforcement; read from right to left.

In another case of myeiitis, the frequency of movement ranged from 6 to 8 in the second, and some of the tracings showed increased frequency of movement as a result of reinforcement (clenching the hands, closing the eyes). It was also noted that when reinforcement was not thus manifested in the tracing it was distinctly appreciable to the observer holding the foot. In one instance the act of clenching the fists was attended with a temporary reduction in the range of movement and slightly increased frequency, though the frequency was still further increased when the hands were released. In the through the gastrocnemius and soleus jointly, when the patient stood erect with the legs well extended on the thighs.

In a case of probable porencephaly, the frequency of movement ranged from $\gamma$ to $\% .3$ in the second, averaging \%.2. In addition to the movements of flexion and extension of the foot that constitute ordinary ankle clonus, lateral movements of the foot also could be induced in this case, and these were found to average 6.5 in frequency, with little variation (Fig. 6).

These observations appear to show that there is a not

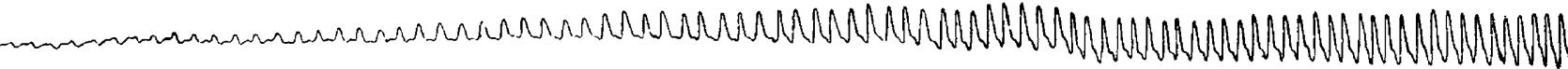

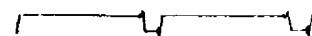

Fig. 4.-Tracings 38, 39, 40. Tracing of ankle clonus from a case clenched; average 7.5 per second. No. 40 , hands relaxed; 6.6 per ally diminishing amplitude, with spontaneous cessation; dicrotic from right to left.

tracings obtained with the aid of a rubber bulb and a tambour, dicrotism was marked, but this, it was thought, might have been due to mechanical influences, as it did not appear in tracings made with the aid of two tambours. The movement in general appeared to be irregular in frequency and extent.

In a case of compression myelitis the average frequency of movement in fifty-six consecutive seconds was 6.48 (6.66 in the first fifteen seconds, 6.46 in the next fifteen seconds, 6.41 in the succeeding seventeen sec-

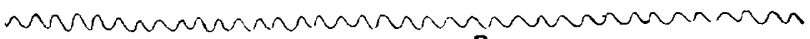
R

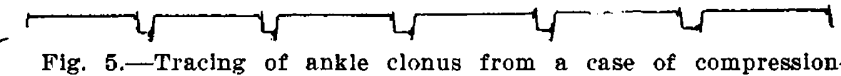
myelitis; made with the ald of two tambours; rate about 6.2 per second; exhibits arrangement of waves in pairs; read from right to left.

onds, and 6.3 in the final nine seconds), thus exhibiting a progressively diminishing tendency. In another tracing (Fig. 5) from the same case the average rate of frequency for twenty-one seconds was 6.24 , with practically no variation, and no appreciable influence was noted from various attempts at reinforcement ( $R$ in Fig. 5), such as closing and opening the eyes, clenching and relaxing one or both hands. Some of the curves exhibited a tendency to arrange themselves in pairs.

In a case of lateral sclerosis in a young man, the in- inconsiderable variation in the frequency of the movement of ankle clonus obtained under different conditions, namely, between 5.8 and 8 in the second. In a healthy person it was from 7 to 7.6 in the second; in a case of hemiplegia, from 6.6 to $\% .2$, averaging 6.9 ; in a case of myelitis, from 6.4 to 8 ; in another case of myelitis, from 6 to 8 ; in a case of compression-myelitis, from 6.2 to 6.7 ; in a case of lateral sclerosis, from 5.8 to 6.9 ; and in a case of probable porencephaly, from 7 to 7.3 . In some cases reinforcement was distinctly

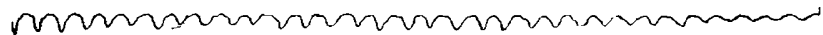

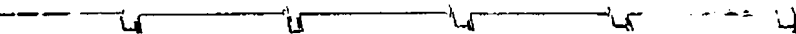

Fig. 6.-Tracing of lateral movement of foot from a case of porencephaly; rate about 6.5 per second; read from right to left.

evident, being appreciable to the examining hand and indicated in the tracings by an increase in the frequency of the movement. The failure to demonstrate this reinforcement with greater constancy may be due, in part at least, to the manner in which the reflex was elicited, the extension of the foot, in degree and vigor, being held somewhat in check by the examining hand, or by the elastic band that was employed for the same purpose, so that the reinforcement in either of these directions escaped record. Ankle clonus can not be induced in the usual manner in healthy individuals, and the movement 
excited by supporting the weight of the body on the ball of the foot requires in some degree the consent, if not the co-operation, of the individual. It is, therefore, to be looked on as an artificial or false clonus, and accordingly as wanting in the significance of the true clonus. The frequency of the former agrees in general with that of the latter.

\section{MEDICAL EDUCATION AND PREIIMINARY REQUIREMENTS.* \\ GEORGE H. SIMMONS, M.D. \\ CHICAGO.}

The subject that I shall discuss to-night is one that has many phases, and one on which all do not agree; however, it is one of vital importance and one in which all are interested. I trust that your deep interest in the subject will influence you to bear with me, even though our opinions may not coincide in every particular.

At no time in the history of our country has there been such an unrest in educational affairs as now. The primary and grammar grades have apparently a sure foundation, and will continue to remain about as they are. But above these grades everything seems to be uncertain. Even the high school, we are told, has not an absolutely certain position. What is to become of the college, however, is the question anxiously asked by those who are in the habit of looking through darkcolored glasses. They are sure that the high school will reach up and the university down till the two meet and the college vanishes. And the university; what is to become of it? Is it to be Germanized and developed into a fraternity of professional schools, or Anglicized, and result in simply a combination of colleges? I do not know, but I feel sure that the university will develop until it fits the needs, the genius and the conditions of our country; that the college will remain a distinctive American institution, consequently a necessity. The unrest now prevailing and the evolution now going on will result, I have not the slightest doubt, in establishing more firmly than ever our present splendid educational system, only more perfect than now, and better adapted to the needs of our people.

If there is an unrest in regard to gencral education, what shall we say of medical education? Unrest is not a sufficiently strong term. Evolution, if not revolution, would better fit the condition.

One of the most prominent signs of the times is the fact that educators are becoming actively interested in a higher standard of medical education, and recognize it as a part of a problem that confronts them. The relation of the professional school to the college and to the university has become so important that a number of conferences have been held by educators to consider the subject, one of the most important in the West being that held last May in Chicago. At this there were represented no less than thirty-two colleges and universities from Massachusetts to California. The report of this conference makes interesting reading, but the most interesting fact revealed to us as medical men is that medical education has become of sufficient importance to engage the attention and earnest consideration of the leading educators of our country. This, I repeat, is encouraging and full of promise for the future.

* An address delivered at the dedication of the new building of the Medical Department of Drake University, Des Moines, Iowa, Jan. 29, 1904.
AN OVERCROWDED PROFESSION.

It may be interesting at the outset to call attention to the fact that our profession is enormously crowded, compared with relative conditions in other countries, and that, if we can deduce anything from educational statistics, this condition is annually becoming worse. At the present time it is estimated that the ratio of physicians to population is one to less than 600 . We have twice as many physicians, in proportion to the population, as England, four times as many as France, five times as many as Germany and six times as many as Italy. Yet in each of these, especially in England, France and Germany, there is a cry of oversupply.

In the year 1880 there were 90 medical colleges in the United States, 11,826 students in attendance and 3,241 graduates. Last year there were 154 medical colleges, 27,615 students in attendance and 5,698 graduates. That is, there has been an increase of 64 colleges in twenty-three years, or 71 per cent. The number of students in attendance has increased by 15,789, or 133 per cent., and the graduates increased 2,456 , or 75 per cent. During the same period the population has increased less than 50 per cent. It is estimated that 1,700 physicians died last year, and that 500 withdrew from practice, either retiring or entering other callings, making a total loss of 2,200 . Let us be liberal and put it at 2,500. This would leave to be added to the profession during 1903 approximately 3,200. Thus there are annually being turned out of our medical colloges twice as many graduates as are required to keep up the present absurdly crowded conditions, even if we allow for the normal increase in population. If the annual output of our medical colleges increases proportionately during the next twenty-three years as it has during the past twenty-three years, it can be easily estimated what the conditions will be then. During the last four years 21,355 young physicians have bcen poured into the ranks of our profession. At least as many entered the colleges during the present college year as graduated from them last year. Hence, during the next four years at least $2 \%, 600$ more will be added, making nearly 50,000 new physicians entering the ranks during the first eight years of the Twentieth century. One is tempted to make harsh critjcisms when one realizes the cause of all this.

In connection with this another phase of the situation should be noticed. In the past there have been openings waiting on the frontier, even though the cities, towns and villages in the settled part of our country were oversupplied. New states and territories were opening up and developing, and these offered alluring possibilities. Here, there and everywhere on the prairies, among the forests and in mountain fastnesses, villages were rising up and developing into towns and cities, offering homes and a livelihood for the courageous and enterprising. To-day all is changed. From the Atlantic to the Pacific, from the tropical shores of the Gulf of Mexico to the cold borderland of the North, it is settled. There is no longer any undiscovered or any undeveloped country. And no matter which way he looks, or where he may go, the young physician will find the field occupied-another physician is there before him. But he squeezes in somewhere, divides up with others, and succeeds, fails or vegetates, depending on the man and his abilities. It is now a case of the survival of the fittest.

But why take this gloomy view, you say; why show this dark side of the picture? Solely to answer at the outset the argument so often made by raising the stand- 